\title{
Validation of High Ocean Surface Winds from Satellites Using Oil Platform Anemometers
}

\author{
Andrew Manaster, LuCreZia Ricciardulli, AND THOMAS MEISSNER \\ Remote Sensing Systems, Santa Rosa, California
}

(Manuscript received 9 July 2018, in final form 21 February 2019)

\begin{abstract}
Reliable sources for validating wind observations made by spaceborne microwave radiometer and scatterometer sensors above $15 \mathrm{~m} \mathrm{~s}^{-1}$ are scarce. Anemometers mounted on oil platforms provide usable wind speed measurements that can help fill this gap. In our study we compare wind speed observations from six microwave satellites (WindSat, AMSR-E, AMSR2, SMAP, QuikSCAT, and ASCAT) with wind speed records from 10 oil platform anemometers in the North and Norwegian Seas that were provided by the Norwegian Meteorological Institute. We study various forms of the vertical wind profile, which is required to convert anemometer winds to a reference height of $10 \mathrm{~m}$ above sea level. We create and analyze matchups between satellite and anemometer winds and find good agreement up to wind speeds of $30 \mathrm{~m} \mathrm{~s}^{-1}$ within the margin of errors. We also evaluate wind speeds from several analyses [ECMWF, NCEP, and Cross-Calibrated Multi-Platform (CCMP)]. We find them to be significantly lower than the anemometer winds with their biases increasing systematically with increasing wind speed. Important components of our analysis include a detailed discussion on the quality control of the anemometer winds and a quantitative analysis of the uncertainties in creating the matchups.
\end{abstract}

\section{Introduction}

Spaceborne active and passive microwave sensors have been monitoring global ocean surface winds for more than three decades (Bourassa et al. 2010; Wentz et al. 2017). These measurements have been extensively validated versus in situ observations from anemometers on moored buoys and are highly accurate in the low to moderate wind regime $\left(0-15 \mathrm{~m} \mathrm{~s}^{-1}\right)$. In this wind regime, wind observations from satellites and buoys, converted to a reference height of $10 \mathrm{~m}$, typically agree within $1.0-1.5 \mathrm{~m} \mathrm{~s}^{-1}$ over the global oceans (Wentz 1997; Mears et al. 2001; Ebuchi et al. 2002; Verspeek et al. 2010; Ricciardulli and Wentz 2015; Wentz et al. 2017).

At higher wind speeds (above $15 \mathrm{~m} \mathrm{~s}^{-1}$ ) there is considerable uncertainty and discrepancy among the various satellite wind datasets as well as between satellite and ground truth observations. This is mainly due to the sparseness of reliable in situ high wind measurements that can be used for calibration and validation of the satellite sensors. The wind speed retrievals of both active (scatterometers) and passive (radiometers) microwave sensors require empirically derived geophysical

Corresponding author: Andrew Manaster, manaster@remss.com model functions (GMFs). The GMF relates the observed satellite signals, which are the radar backscatter for the active sensors and the ocean surface emissivity for the passive sensors, to the ocean surface wind speeds at $10 \mathrm{~m}$. The lack of reliable high wind speed observations makes the tuning of GMFs at high wind speeds challenging. As a consequence, even wind speed products derived from the same sensor but processed by different institutions can differ significantly when different GMFs or different calibrations are used in their retrievals. For example, three wind speed products are available for the EUMETSAT C-band scatterometer ASCAT, each of which are based on three different GMFs: 1) the operational Royal Netherlands Meteorological Institute (KNMI) ASCAT (Verhoef et al. 2008; Stoffelen et al. 2017), whose high wind GMF [C-band model (CMOD) 5.n (CMOD5.n), recently updated to CMOD7] calibration uses a combination of European Centre for Medium-Range Weather Forecasts (ECMWF) model and buoy winds; 2) NOAA ASCAT (Soisuvarn et al. 2013), whose high wind GMF (CMOD5.h) uses aircraft data for calibration; 3) Remote Sensing Systems (RSS) ASCAT (Ricciardulli 2016; www.remss.com/missions/ ascat/), whose high wind GMF is based on intercalibration with radiometers. The radiometer winds themselves 
were calibrated using data from the NOAA Atlantic Oceanographic and Meteorological Laboratory Hurricane Research Division (Meissner and Wentz 2009, 2012). When compared, KNMI ASCAT displays much lower winds than NOAA ASCAT and RSS ASCAT in the high wind regime. The difference reaches as much as $20 \%$ at $25 \mathrm{~m} \mathrm{~s}^{-1}$ (Soisuvarn et al. 2013; Pineau-Guillou et al. 2018).

While buoy measurements are considered the gold standard for validating winds below $15 \mathrm{~m} \mathrm{~s}^{-1}$, their validity at wind speeds above $15-20 \mathrm{~m} \mathrm{~s}^{-1}$ is questionable. This is due to the fact that buoy anemometer observations might be affected by high sea state, wave sheltering, buoy tilting, and other effects (Large et al. 1995; Zeng and Brown 1998; Skey and Miles 1999; Taylor and Yelland 2001; Howden et al. 2008; R. Bouchard 2017, personal communication).

For very high winds above $25 \mathrm{~m} \mathrm{~s}^{-1}$ (i.e., storm and hurricane force winds), dropsonde measurements taken from aircraft flying into the storms provide what is accepted as optimal ground truth. Measurements along the flight paths of the Stepped Frequency Microwave Radiometers (SFMRs; Uhlhorn and Black 2003; Uhlhorn et al. 2007; Klotz and Uhlhorn 2014) mounted on hurricane-penetrating aircrafts are calibrated to the dropsondes (Klotz and Uhlhorn 2014) and provide a method for transferring the calibration from pointwise dropsonde observations to satellite measurements on wide swaths of several hundred kilometers. This strategy has been used to validate wind speeds in tropical cyclones (TCs) measured by two L-band radiometers: Soil Moisture Ocean Salinity (SMOS; Reul et al. 2016) mission and Soil Moisture Active Passive (SMAP; Fore et al. 2016; Meissner et al. 2017) mission. The wind emissivity signal at $\mathrm{L}$ band is largely caused by emission from whitecaps, which results in good sensitivity even at extreme winds found in category 5 TCs. Moreover, the L-band emission is only minimally affected by precipitation. Obtaining reliable measurements of satellite wind speeds in TCs from all other microwave radiometers and scatterometers is very challenging, as they are affected by rain, or they lose sensitivity at these very high winds.

An indirect method for validating wind speeds in TCs is to compare the estimates of the storm radii at fixed wind speeds, determined from satellite measurements, to direct measurements from aircrafts or model forecasts based on assimilated observations (Meissner et al. 2017; Reul et al. 2017). This has also been done for L-band radiometers. The estimates of the 17.5, 25, and $34 \mathrm{~m} \mathrm{~s}^{-1}$ storm radii from SMAP are now ingested in the Automated Tropical Forecasting System (ATCF; Sampson and Schrader 2000) at the U.S. Navy (https:// www.nrlmry.navy.mil/atcf_web/index.html) and the Joint
Typhoon Warning Center (http://www.metoc.navy.mil/ jtwc/jtwc.html).

It becomes apparent that verifying the validity of satellite wind speeds from 15 to $25 \mathrm{~m} \mathrm{~s}^{-1}$ is very important for reconciling major inconsistencies among different datasets. It is also necessary to help bridge the gap between the measurements and GMFs at low-moderate wind speeds to those at even higher wind speeds in TCs.

One way of pursuing this goal is to use wind speed measurements from aircrafts flying into extratropical storms, which are less affected by rain than TCs. Meissner and Wentz (2012) and Ricciardulli and Wentz (2015) showed that observations from the polarimetric radiometer WindSat and the scatterometer QuikSCAT compare well with aircraft turbulent probe wind observations off Greenland (Renfrew et al. 2009) in the range of $15-25 \mathrm{~m} \mathrm{~s}^{-1}$. However, this aircraft dataset only provided a very limited number of observations, as they were often too close to land or sea ice where satellite retrievals are not accurate.

A good source of potentially reliable high wind observations is provided by anemometers mounted on oil platforms in the Norwegian and North Seas, which experience intense extratropical cyclones and high winds in the winter seasons. The goal of our study is to perform an extensive intercomparison between satellite and oil platform high winds from an 18-yr record of wind measurements from platforms off the coast of Norway. The platform observations have been archived by the Norwegian Meteorological Institute. The oil platform anemometers are mounted at different heights between 40 and $140 \mathrm{~m}$, and their measurements need to be converted to a height of $10 \mathrm{~m}$ in order to make a meaningful comparison with the satellite winds. This conversion to $10 \mathrm{~m}$ is a critical aspect of any comparison involving platform winds, as it is sensitive to the assumptions made about the atmospheric stability at the platform location and about the vertical wind profile. A detailed and thorough study by Furevik and Haakenstad (2012) compared platform anemometer winds and radiosonde measurements of vertical wind profiles in the Norwegian and North Seas and found good agreement, on average, when using a vertical profile close to neutrally stable.

Some comparisons between wind observations from oil platforms and satellites have already been performed by other authors. Zabolotskikh et al. (2014) found very good agreement between winds from the AMSR2 radiometer, which were processed by Satellite Oceanography Laboratory (SOLab; Russian State Hydrometeorological University), versus one year of observations from eight oil platforms in the North and Norwegian Seas. The platform winds were quality controlled and converted to $10 \mathrm{~m}$ using available measurements to determine the 
atmospheric stability conditions. Pineau-Guillou et al. (2018) used data from 67 oil platforms in the North Atlantic, provided by the Global Telecommunication System (GTS) and the Norwegian Meteorological Institute archive, and compared them to several satellite datasets: SOLab AMSR2, KNMI ASCAT, RSS ASCAT, WindSat, SMOS, and the Jason-2 altimeter, and to buoys moored in the North Atlantic. The study by PineauGuillou et al. (2018) was limited to a few sample cases of winter storms. The quality control (QC) and the method of converting the platform winds to a height of $10 \mathrm{~m}$ that were used in their study are not described in detail. They found that all datasets were consistent with the platform wind speeds with the exception of the buoys and KNMI ASCAT. All the datasets were also compared to winds from the ECMWF analysis. These analysis winds were found to be significantly lower than the platform winds and in line with the KNMI ASCAT and buoys at high wind speeds. This result is not surprising, considering that the GMF for KNMI ASCAT has been calibrated to ECMWF and buoy wind speeds.

Our study builds on these results and aims at reinforcing the confidence in the platform wind observations and their comparison to satellite data. Our comparison is based on matchups of oil platform winds with six satellite wind products for an extended time period between 1999 and 2016. All satellite winds used in our study are processed at Remote Sensing Systems and have been intercalibrated at high wind speeds to a good level of accuracy. These include the scatterometers QuikSCAT and ASCAT and the radiometers AMSR-E, AMSR2, SMAP, and WindSat. Additionally, wind fields from two forecast models, NCEP and ECMWF, and a satellite-based wind assimilation [Cross-Calibrated Multi-Platform (CCMP)] were compared to the platform winds.

Our paper is organized as follows: The datasets are described in section 2 . The quality control and methods for converting the platform winds to $10 \mathrm{~m}$ are presented in detail in section 3. The comparisons and the implication of the results are presented in section 4 . Section 5 contains a discussion of the sources of uncertainties in each dataset. This section also provides quantitative estimates for these uncertainty sources. Summary and conclusions are given in section 6.

\section{Datasets}

\section{a. Platform anemometer wind speeds}

The platform wind data used in this experiment were obtained from anemometers positioned on 10 different oil platforms located in the North and Norwegian Seas (Fig. 1) and encompassed varying time periods between January 1999 and October 2016. Most platforms had more than one anemometer set up at different heights between 40 and $140 \mathrm{~m}$. The platform data files were provided by the Norwegian Meteorological Office and contained the following information for each anemometer: wind speed measured at the height of the anemometer, wind speed adjusted to a height of $10 \mathrm{~m}$, and wind direction relative to north. The wind speed and direction values in the files were reported as 10- or 20-min or hourly averages, depending on the platform/time period. The conversion to 10 -m equivalent winds was performed by the Norwegian Meteorological Office using the wind power law:

$$
W_{10 \mathrm{~m}}=W_{H}\left(\frac{10 \mathrm{~m}}{H}\right)^{\alpha}
$$

where $W_{10 \mathrm{~m}}$ is the $10-\mathrm{m}$ wind, $W_{H}$ is the wind at the height of the anemometer, $H$ is the height of the anemometer (in $\mathrm{m}$ ), and the exponent $\alpha$ is an empirically determined coefficient that defines the shape of the wind profile. The Norwegian Meteorological files have used a value of $\alpha=0.13$ to convert from $H$ to $10 \mathrm{~m}$. We will discuss the methodology behind the $10-\mathrm{m}$ conversion in detail in section 3 .

\section{b. Satellite wind speeds}

For comparison with platform anemometers, wind speeds retrieved from six different microwave satellite radiometers and scatterometers were used. These wind speed datasets are produced and distributed by RSS (www.remss.com). They include measurements from the following polar-orbiting satellites: AMSR2 (Wentz et al. 2014a), AMSR-E (Wentz et al. 2014b), SMAP (Meissner et al. 2018), and WindSat (Wentz et al. 2013) radiometers and the ASCAT (Ricciardulli and Wentz 2016) and QuikSCAT (Ricciardulli et al. 2011) scatterometers. These satellite winds are reported as $10-\mathrm{m}$ equivalent neutral winds (Liu and Tang 1996). The resolution of these wind speed retrievals ranges from 25 to $40 \mathrm{~km}$. The data are then gridded into $0.25^{\circ}$ global maps, available twice daily. SMAP and WindSat data are gridded using a Backus-Gilbert optimum interpolation (Stogryn 1978; Poe 1990). ASCAT, QuikSCAT, AMSR2, and AMSR-E are simply averaged to a $0.25^{\circ}$ global map from swath data produced at their original resolution. The missions span various time periods, ranging from 1999 until present. These winds were collocated with platform winds during all available overlapping time periods. The collocation process is described in detail in section 3. In creating the matchups, the satellite observations were filtered for rain, as precipitation degrades the quality of both radiometer wind speeds (Wentz and Spencer 1998; Hilburn and Wentz 2008; Meissner and Wentz 2009) and scatterometer wind speeds (Stiles and Yueh 2002; 


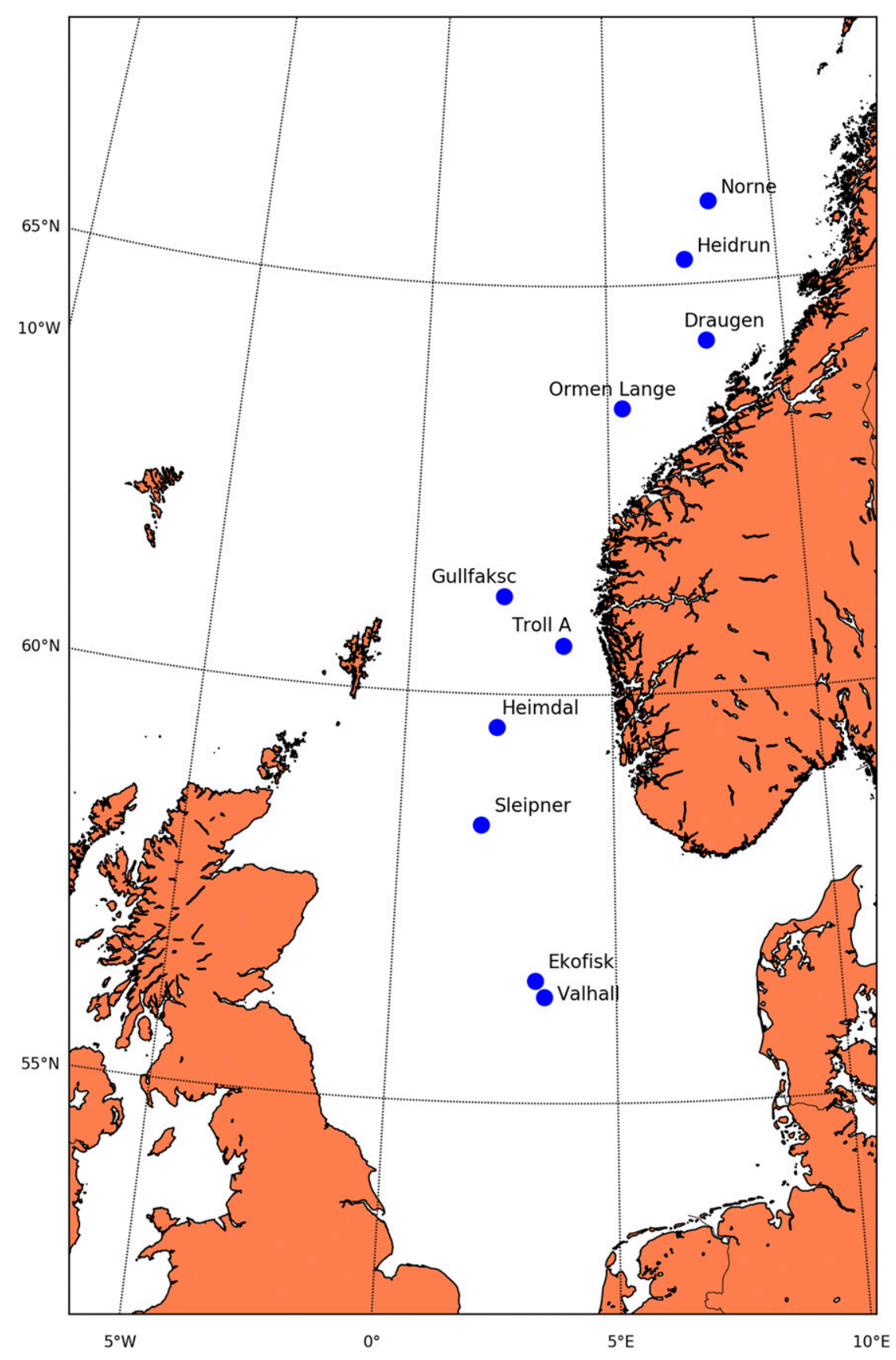

FIG. 1. Locations of the 10 platforms in the North Sea used in this study.

Tournadre and Quilfen 2003; Draper and Long 2004; Hilburn et al. 2006; Weissman and Bourassa 2008; Portabella et al. 2012). The exception is the L-band radiometer SMAP, whose wind retrievals are only minimally affected by rain (Meissner et al. 2017).

\section{c. Analysis wind speeds}

Along with satellite data, wind speed data from various model analyses were collocated with and compared to platform anemometer winds. These included the following:

1) The 6-hourly ECMWF operational analysis winds (www.ecmwf.int), which are sampled to a $1^{\circ} \times 1^{\circ}$ grid. The ECMWF wind speeds correspond to $10 \mathrm{~m}$ above the ocean surface but not to neutral stability conditions. This does not pose a major concern for our analysis as the difference between 10-m neutral and 
10-m nonneutral stability winds is on the order of $0.4 \mathrm{~m} \mathrm{~s}^{-1}$ or less in the locations that we are considering (Hersbach 2008; 2010).

2) The NCEP Global Data Assimilation System (GDAS) Final Analysis winds, which are produced on both $1^{\circ} \times 1^{\circ}$ and $0.25^{\circ} \times 0.25^{\circ}$ grids 4 times daily (nomads.ncep.noaa.gov/). The $1^{\circ}$ NCEP GDAS winds are available for the whole period of this analysis (1999-2016), while the $0.25^{\circ}$ NCEP GDAS winds were available from the beginning of 2015 onward.

3) The CCMP gridded surface vector winds, version 2.0: This level 4 product is a satellite-based wind assimilation of radiometer and scatterometer winds processed at RSS, and moored buoy winds. The data are assimilated using a two-dimensional variational data assimilation (2D-VAR) method which uses model wind data provided by ERA-Interim as a background field. The final product is a global dataset of ocean surface $(10 \mathrm{~m})$ vector winds on a $0.25^{\circ} \times 0.25^{\circ}$ grid, 4 times daily (Atlas et al. 2011; Wentz et al. 2015; www.remss.com/measurements/ccmp/), which is available from 1987 to the present day.

\section{Matchups and quality control}

Before creating the matchups between platform and satellite/model winds, a series of rigorous quality checks were performed on the platform winds. This was done in order to increase confidence in the conclusions of the present analysis. This quality control aimed at eliminating any bad or spurious data that may have been present in the anemometer data files and made sure that the comparison with satellite/model data was performed on measurements with consistent spatial and temporal scales.

\section{a. Derivation of anemometer height}

Since satellite and model analysis winds are reported at a height of $10 \mathrm{~m}$, platform anemometer winds must be converted from each anemometer height to $10-\mathrm{m}$ equivalent winds making some assumptions about the vertical wind profiles. It is worth reiterating that while anemometer 10-m equivalent winds are available in the data files provided by the Norwegian Meteorological Office, they were calculated using only one specific choice of the vertical profile [(1) with $\alpha=0.13$ ]. Part of this study focuses on determining the sensitivity of anemometer-satellite comparisons to the choice of vertical wind profile used to convert platform wind measurements from the anemometer height to a height of $10 \mathrm{~m}$. Therefore, instead of using the precalculated $10-\mathrm{m}$ platform winds, we explored different vertical profiles by using the original wind observations at the anemometer height.
As noted earlier, the wind speeds measured at the height of the anemometer were provided in the platform data files. Unfortunately, the actual anemometer heights were not. However, these heights can be retrieved simply by solving (1) with $\alpha=0.13$ for $H$. Using this method, anemometer heights were retrieved at each 10- or 20-min or hourly interval for the entire time series of each anemometer on each platform. It was found that some anemometers were relocated to different heights between 1999 and 2016. For example, the anemometer WIA on the platform Ekofisk was located at a height of approximately $69 \mathrm{~m}$ from January 1999 to June 2014 and a height of $103 \mathrm{~m}$ from June 2014 to October 2016. As such, these two were treated as separate time series for the purpose of calculating $10-\mathrm{m}$ wind speeds. That means that the winds measured by Ekofisk WIA from January 1999 to June 2014 and the winds measured by Ekofisk WIA from June 2014 to October 2016 were converted to their $10-\mathrm{m}$ equivalents separately using their respective anemometer heights. Altogether, this separation of anemometers by platform and subsequently height created 37 different wind speed time series spanning various time periods between 1999 and 2016. These were then used for collocation with satellite and model data. Table 1 lists these time series for the WindSat-platform anemometer matchups.

\section{b. Wind vertical profiles}

After retrieving the original anemometer height, platform wind speeds were converted to $10-\mathrm{m}$ winds for each of the 37 time series using different assumptions for the vertical profile. The various forms of the vertical profiles that we examined were the power-law profile (1) with different values for $\alpha$ as well as a logarithmic wind profile:

$$
W_{10 \mathrm{~m}}=W_{H}\left[\frac{\ln \left(\frac{10 \mathrm{~m}}{Z_{0}}\right)}{\ln \left(\frac{H}{Z_{0}}\right)}\right] .
$$

This vertical profile (2) is frequently used for calculating $10-\mathrm{m}$ winds from measurements at other heights, for example, for buoys (Mears et al. 2001). In (2), $W_{10 \mathrm{~m}}$ is the $10-\mathrm{m}$ wind, $W_{H}$ is the wind at the height of the anemometer, and $H$ is the height of the anemometer (in $\mathrm{m}$ ) $Z_{0}=1.52 \times 10^{-4} \mathrm{~m}$ is the empirically determined value for the surface roughness length (Peixoto and Oort 1991). In our study, we use this constant value for $Z_{0}$ and assume that it is independent of wind speed.

Furevik and Haakenstad (2012) have performed a thorough analysis of several of the Norwegian platform anemometers. They first validated the anemometer 
TABLE 1. The individual time series of the WindSat-platform anemometer wind speed matchups including the statistics (number of observations, bias, standard deviation, and Pearson correlation coefficient) of the intercomparison between the two data sources. The bias is the difference between WindSat wind speed and platform anemometer wind speed. The list contains observations for which the average between WindSat and anemometer wind speed lies between 5 and $25 \mathrm{~m} \mathrm{~s}^{-1}$.

\begin{tabular}{|c|c|c|c|c|c|c|}
\hline Platform & Years & Height (m) & No. of observations & $\operatorname{Bias}\left(\mathrm{m} \mathrm{s}^{-1}\right)$ & $\operatorname{Std} \operatorname{dev}\left(\mathrm{m} \mathrm{s}^{-1}\right)$ & Pearson correlation \\
\hline Draugen WIA & $2003-16$ & 78 & 9822 & -0.27 & 2.05 & 0.84 \\
\hline Draugen WIB & $2003-16$ & 78 & 7976 & -0.15 & 1.96 & 0.85 \\
\hline Ekofisk WIA & 1999-2014 & 69 & 7842 & -0.75 & 1.69 & 0.88 \\
\hline Ekofisk WIA & 2014-16 & 103 & 1668 & -0.75 & 1.71 & 0.89 \\
\hline Ekofisk WIB & 2003-16 & 115 & 9194 & -0.81 & 2.03 & 0.85 \\
\hline Ekofisk WIC & 2014 & 103 & 80 & -0.76 & 1.22 & 0.87 \\
\hline Gullfaks-C WIA & $2003-10$ & 100 & 4309 & -0.05 & 1.75 & 0.90 \\
\hline Gullfaks-C WIA & $2010-16$ & 1050 & 5188 & 0.43 & 1.86 & 0.86 \\
\hline Gullfaks-C WIB & 2003-06 & 142 & 1961 & -0.66 & 1.73 & 0.91 \\
\hline Gullfaks-C WIB & 2006-16 & 140 & 7463 & -0.18 & 1.78 & 0.89 \\
\hline Heidrun WIA & 2003-09 & 87 & 4882 & 2.29 & 3.02 & 0.62 \\
\hline Heidrun WIA & 2009-16 & 131 & 5551 & -0.09 & 1.82 & 0.87 \\
\hline Heidrun WIB & $2003-16$ & 131 & 10425 & -0.04 & 1.94 & 0.86 \\
\hline Heidrun WIC & 2003-16 & 131 & 10339 & -0.11 & 1.86 & 0.87 \\
\hline Heidrun WID & 2003 & 131 & 51 & -0.51 & 1.34 & 0.92 \\
\hline Heidrun WID & 2003-06 & 87 & 2095 & 0.56 & 2.93 & 0.72 \\
\hline Heimdal WIA & $2003-16$ & 71 & 7771 & 0.23 & 2.02 & 0.85 \\
\hline Heimdal WIB & 2003-16 & 71 & 7861 & -0.18 & 1.70 & 0.89 \\
\hline Norne WIA & 2003-09 & 43 & 4962 & -0.41 & 1.75 & 0.89 \\
\hline Norne WIA & $2013-16$ & 47 & 2464 & -0.22 & 1.69 & 0.89 \\
\hline Norne WIB & $2003-09$ & 43 & 4961 & -0.09 & 1.62 & 0.89 \\
\hline Norne WIB & 2010-16 & 47 & 5295 & 0.59 & 1.70 & 0.87 \\
\hline Norne WIC & 2010-16 & 47 & 5493 & 0.36 & 1.97 & 0.85 \\
\hline Ormen Lange WIA & $2007-09$ & 45 & 952 & 0.45 & 2.71 & 0.81 \\
\hline Ormen Lange WIB & 2010-13 & 47 & 2587 & 0.23 & 3.31 & 0.62 \\
\hline Sleipner WIA & $2003-13$ & 136 & 7575 & -0.92 & 1.95 & 0.88 \\
\hline Sleipner WIB & 2003-13 & 136 & 7649 & -0.96 & 1.94 & 0.88 \\
\hline Valhall WIA & $2007 / 08$ & 78 & 884 & -0.98 & 1.80 & 0.85 \\
\hline Valhall WIA & 2011-16 & 120 & 3573 & -0.82 & 1.91 & 0.86 \\
\hline Valhall WIB & 2011-16 & 90 & 3550 & 0.96 & 2.53 & 0.74 \\
\hline Valhall WIC & 2007-11 & 39 & 2424 & 1.09 & 2.71 & 0.65 \\
\hline Valhall WIC & 2011-16 & 50 & 3522 & 0.67 & 2.56 & 0.73 \\
\hline Valhall WID & $2008-10$ & 81 & 629 & -0.98 & 1.85 & 0.87 \\
\hline Valhall WID & $2010-11$ & 66 & 1147 & -0.96 & 2.11 & 0.79 \\
\hline Valhall WID & 2011-16 & 50 & 3524 & 1.25 & 2.53 & 0.71 \\
\hline
\end{tabular}

measurements by comparing them with observations made by radiosondes, which were deployed at the anemometer site. They then took wind profiles from 8720 radiosonde observations and parsed them into neutrally stable, unstable and stable atmospheric conditions according to the vertical profiles of air temperature, which were also measured by the radiosondes. They found that the vertical wind profile can be best described by a power law (1) with a coefficient $\alpha=0.06$ if the atmosphere is neutrally stable, $\alpha=0.04$ if the atmosphere is unstable, and $\alpha=0.09$ if the atmosphere is stable. About $87 \%$ cases in their study fell into the neutrally stable category. Kettle (2015) studied the atmospheric stability conditions for the Norwegian platforms over a 3 -yr period and found the majority of cases were in the neutrally stable range. That means that a power-law profile with $\alpha=0.06$ can be expected to provide a very good overall fit for the wind profiles under consideration.

Our first task was to test and confirm this result by comparing the $W_{10 \mathrm{~m}}$ observations from the platform anemometers with the satellite observations for low and moderate wind speeds $\left(5-15 \mathrm{~m} \mathrm{~s}^{-1}\right)$ for various vertical profiles. There are many matchups in this wind speed range and we also know that the satellite wind speeds between 5 and $15 \mathrm{~m} \mathrm{~s}^{-1}$ are very accurate and match moored buoy measurements, which have long been considered the ground truth for these wind speeds (Wentz et al. 2017). We have calculated 10-m platform winds $W_{10 \mathrm{~m}}$ based on the measurements $W_{H}$ and the values of $H$ (section 3a) using the wind power law (1) with different $\alpha$ values, ranging from 0.04 to 0.13 . We have also tested the logarithmic wind profile (2). 
Our results in section 4 will confirm that the power law with $\alpha=0.06$ indeed provides the best fit for the vertical wind profile in accordance with the study of Furevik and Haakenstad (2012). It is therefore justified to use this wind profile when comparing satellites and platform anemometers at higher wind speeds (above $15 \mathrm{~m} \mathrm{~s}^{-1}$ ), where the accuracy of the satellite wind speeds has not yet been established and where we intend to validate the satellite winds against the platform anemometers.

\section{c. Temporal averaging}

Before collocations between the platform anemometers and satellite/model data were performed, all platform winds were averaged to hourly values. This hourly averaging helped make the point source platform measurements more consistent with the spatial and temporal scales associated with satellite/model measurements thereby making the comparison between the two more meaningful. Collocations between each of the satellites and the wind platforms were then performed only for satellite measurements that were within $1 \mathrm{~h}$ of a platform anemometer measurement, for the $0.25^{\circ}$ grid box that the platform was located in, and in the absence of rain. Collocations between model analysis data and platforms were done by temporal and spatial interpolation of the 6-hourly wind data to the platform anemometer measurement time and the platform location. It should be noted that no collocations were done with the anemometers on the Troll-A platform due to its close proximity to land as microwave satellite sensors there are less reliable due to land contamination in the observed microwave signal.

\section{d. Basic statistics of satellite-anemometer matchups}

For each anemometer time series and each satellite or analysis, three joint probability distribution functions (PDFs) were plotted: one for the 10-m wind determined using the logarithmic wind profile (2) and two for the conversion to $10 \mathrm{~m}$ using the power law (1) with $\alpha=0.06$ and $\alpha=0.13$. These three cases were all compared to satellite/analysis winds. An example of one of these comparisons is shown in Fig. 2, which displays the joint PDFs for wind speeds calculated at the platform Draugen, anemometer WIA versus WindSat wind speeds from the period 2003-16. WindSat was selected as the satellite of choice for comparison with wind platforms because it offers the longest time series among the six satellite sensors used in this study (13 years, from 2003 to 2016). All figures shown in this section are based on comparisons between WindSat and various platform anemometers.

The first thing to note from Fig. 2 is the noticeable difference between the power law with $\alpha=0.13$ winds and the other two platform wind conversions. While both the $\log$ winds and the power law with $\alpha=0.06$ winds are relatively consistent with WindSat, the power law with $\alpha=0.13$ winds are significantly lower than WindSat even at low and moderate wind speeds between 5 and $15 \mathrm{~m} \mathrm{~s}^{-1}$, where the accuracy of WindSat wind speeds is undisputed. The average biases for WindSat minus the logarithmic profile winds, power-law profile with $\alpha=0.06$ winds, and power-law profile with $\alpha=0.13$ winds are $0.18,-0.27$, and $1.08 \mathrm{~m} \mathrm{~s}^{-1}$, respectively, for this particular site and anemometer. The corresponding standard deviations are 1.99, 2.05, and $1.90 \mathrm{~m} \mathrm{~s}^{-1}$, respectively. The bias between WindSat and the $\alpha=0.13$ power-law winds increases with increasing wind speed and the slope of the linear best fit deviates from that of the one-to-one line. At $15 \mathrm{~m} \mathrm{~s}^{-1}$, the bias exceeds $2 \mathrm{~m} \mathrm{~s}^{-1}$. The larger biases and worse linear fits for the $\alpha=0.13$ winds when compared to WindSat and other satellites was consistently observed across all 37 platform anemometer time series. Furthermore, the $\alpha=0.13$ winds tend to have lower correlation coefficients than both the $\alpha=0.06$ and the logarithmic profile winds when compared to satellite winds. All of this suggests that the power law with $\alpha=0.13$ does not realistically represent the vertical wind profile typical of the North Sea.

An example of a site where platform anemometer winds do not compare well with WindSat for all 10-m winds, even in the low-moderate wind speed range, is shown in Fig. 3. In comparison to Fig. 2, the 10-m winds calculated in Fig. 3 show significantly larger biases and standard deviations when compared with WindSat. The average biases are 2.69, 2.29, and $3.50 \mathrm{~m} \mathrm{~s}^{-1}$ and the standard deviations are $2.96,3.02$, and $2.84 \mathrm{~m} \mathrm{~s}^{-1}$ for logarithmic profile, $\alpha=0.06$ power law, and $\alpha=0.13$ power law, respectively. We found that if winds measured by a certain anemometer did not compare well to one satellite or analysis, then they generally did not compare well to every other satellite and model analysis. Therefore, in the context of this analysis, this collective disagreement was considered to be an indication of a problem with the anemometer at the site. There are possible reasons why some of the anemometers might render inaccurate wind speed measurements, which we will discuss in more detail in section 5 .

\section{e. Criteria for rejecting data}

Based on these basic statistical results, we have decided to discard anemometer observations whose $10-\mathrm{m}$ wind speeds had a correlation coefficient of less than 0.75 compared to any given satellite or analysis wind. As an additional step in the quality control of the platform anemometer data, the stability of the wind time series for each anemometer at each platform over time was 


\section{0m Wind Speed vs. Windsat Wind Speed draugen, WIA, 2003-2016, Sensor Hgt = 78.00m}
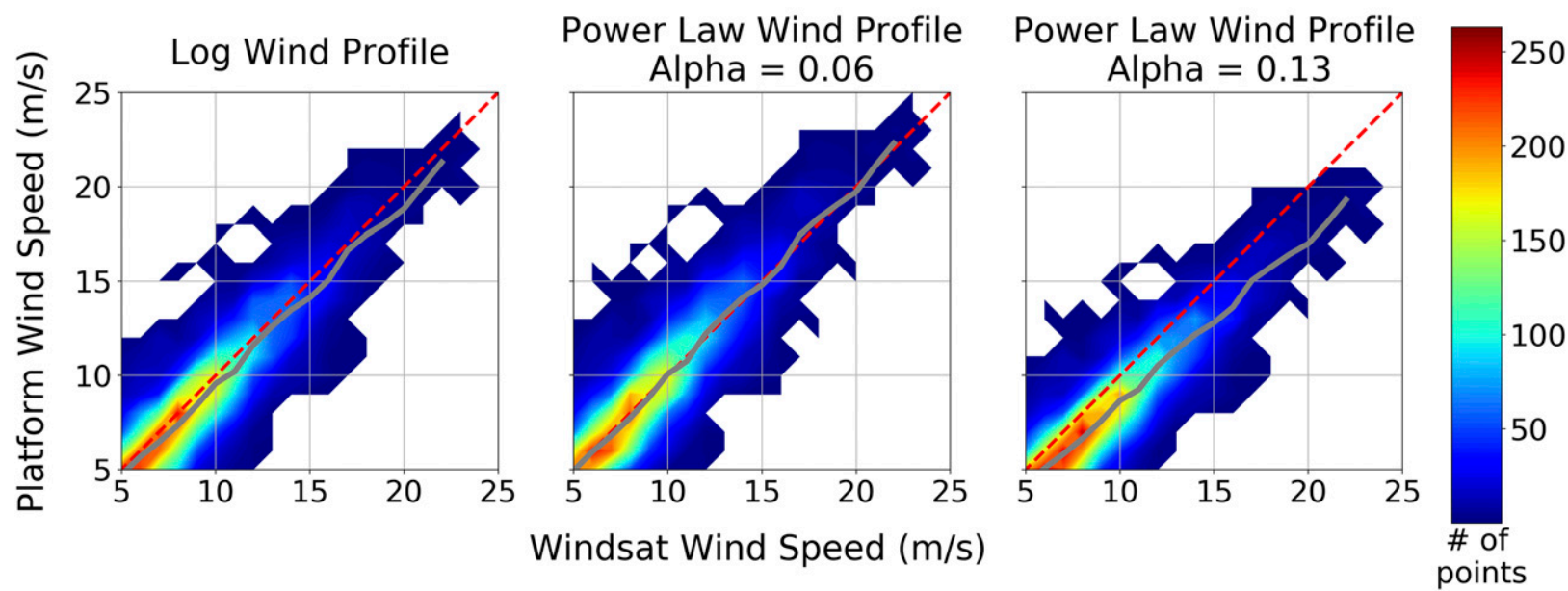

FIG. 2. Two-dimensional PDFs of collocations between the Draugen anemometer WIA and WindSat 10-m winds from 2003 to 2016. (left) Logarithmic wind profile (2). Power-law (1) wind profile with (middle) $\alpha=0.06$ and (right) $\alpha=0.13$. The gray lines represent the relative bias between the WindSat and platform winds. The dashed red lines indicate the ideal cases (no bias).

investigated by comparing them to the collocated satellite/model winds. For instance, Fig. 4 shows the bias time series for WindSat versus the $\alpha=0.06$ power-law $10-\mathrm{m}$ winds for every anemometer at the Heidrun site from 2003 to 2016. From the plot, it can be seen that the time series of Heidrun anemometer WIA from 2003 to 2009 (located at a height of $87 \mathrm{~m}$ ) and Heidrun WID from 2003 to 2006 (also located at a height of $87 \mathrm{~m}$ ) both show biases compared with WindSat that are larger than those for other anemometers. A close look at the joint PDFs (Fig. 3 for Heidrun WIA 2003-09; not shown for Heidrun WID 2003-06) for both of these anemometers showed that all three different conversions to $10-\mathrm{m}$ winds had correlations with WindSat lower than 0.75 thereby confirming the low quality of these specific anemometers.

\section{$10 \mathrm{~m}$ Wind Speed vs. Windsat Wind Speed heidrun, WIA, 2003-2009, Sensor Hgt $=87.00 \mathrm{~m}$}

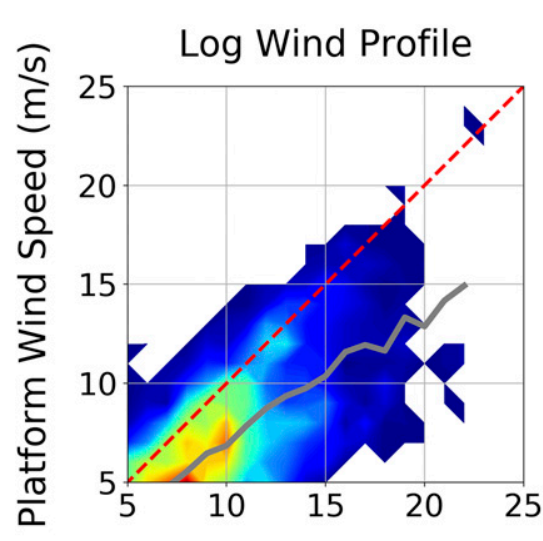

Power Law Wind Profile

$$
\text { Alpha }=0.06
$$

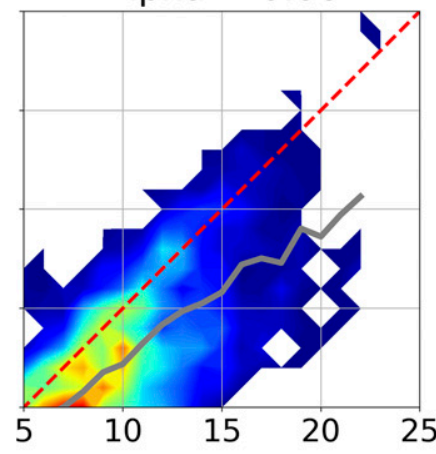

Windsat Wind Speed $(\mathrm{m} / \mathrm{s})$
Power Law Wind Profile
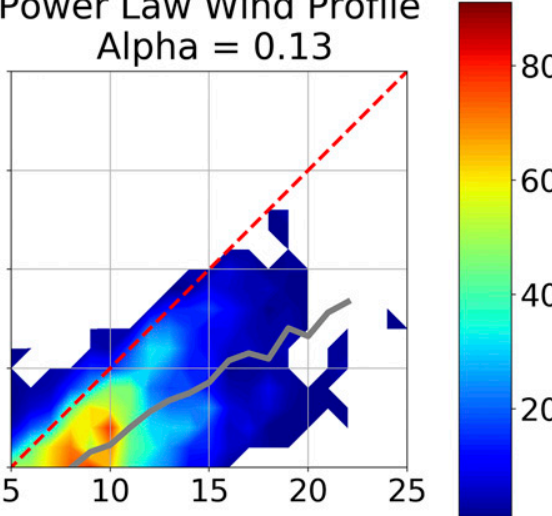

80

60

40

20

points

FIG. 3. As in Fig. 2, but for collocations between Heidrun anemometer WIA and WindSat 10-m winds from 2003 to 2009. 


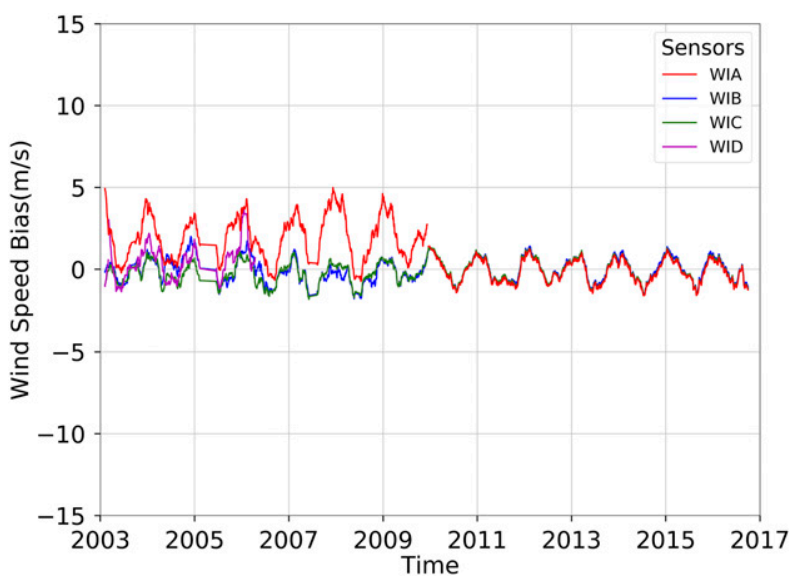

FIG. 4. Time series of WindSat-anemometer biases over time for the 4 different anemometers at the Heidrun platform: WIA (red), WIB (dark blue), WIC (green), WID (purple). The 10-m anemometer winds were calculated using the power law wind profile (1) with $\alpha=0.06$. The red line from 2003 to 2009 (Heidrun WIA) is the same time series whose PDF is plotted in Fig. 3.

In summary, if an anemometer time series displayed a linear correlation coefficient of less than 0.75 with any of the satellites or models, it was not included in the final analyses. Anemometers that showed poor stability of the wind time series in comparison to satellite and model data but had not been previously removed due to correlation coefficients greater than 0.75 were also rejected. It is worth noting that these anemometers removed due to poor stability of the wind time series tended to have low correlation coefficients close to 0.75. After these quality checks were applied, 24 of the original 37 anemometer time series remained for our analysis; however, since the amount of data contained in each time series could vary considerably, the total fraction of rejected platform anemometer observations was only about $25 \%$.

\section{f. Sensitivity of bias to wind direction}

We performed a final quality check on platform anemometer data to examine possible biases related to wind direction. It has been suggested that the location of the anemometer on the oil platform itself could cause it to be the subject of wind speed biases when the wind is blowing from a certain direction (M. Bourassa 2017, personal communication), which could cause distortion of the wind flow. Since wind direction was given in the data files provided by the Norwegian Meteorological Office, biases between WindSat and the three types of converted $10-\mathrm{m}$ wind speeds were stratified by wind direction. We parsed the biases into twelve $30^{\circ}$ bins ranging from $0^{\circ}-30^{\circ}$ to $330^{\circ}-360^{\circ}$ for each of the 24 anemometer time series that passed the quality checks detailed in section 3e. Figures $5 \mathrm{a}-\mathrm{c}$ show how these wind speed biases vary among $30^{\circ}$ bins for the site Gullfaks-C, anemometer WIB from 2006 to 2016. Figure 5d shows the percentage of the total measurements that fall within each $30^{\circ}$ bin for that same site. From Fig. 5 two things can be seen: the biases for the power law with $\alpha=0.06$ (Fig. 5b) winds seem to have the smallest magnitude of all three converted $10-\mathrm{m}$ platform winds, and there is no apparent large bias in any one direction for any of the 10 -m platform winds. This is generally the case for all 24 selected time series that passed the QC; however, there are a few exceptions. In rare cases where large biases were seen in directional bins, it was found that bins that contained these relatively large biases contained some of the fewest, if not the fewest, of the total percentage of wind speed measurements for a given site. Their contribution to the total bias was negligible in all instances.

\section{Results and discussion}

\section{a. Binned statistics for WindSat-anemometer matchups}

The statistics for the individual time series of the WindSat-anemometer matchups are listed in Table 1. Figure 6 displays the relative bias between WindSat and the 10-m platform anemometer winds that passed all the quality control described in section 3 . In this figure, the bias from each available WindSat-anemometer collocation from 2003 to 2016 for each anemometer time series that passed the QC was binned according to the average WindSat-anemometer wind speed. Each of the bins is $1 \mathrm{~m} \mathrm{~s}^{-1}$ wide in the wind speed range from 0 to $23 \mathrm{~m} \mathrm{~s}^{-1}$. To have sufficiently populated bins, we concatenated the highest wind speeds into larger bins (23-25 and $\left.25-30 \mathrm{~m} \mathrm{~s}^{-1}\right)$. It can be seen in this figure that there is very good agreement between WindSat and all anemometers at wind speeds from 0 to $30 \mathrm{~m} \mathrm{~s}^{-1}$, with the bias at the highest wind speed bin being approximately $1 \mathrm{~m} \mathrm{~s}^{-1}$. This is well within a $10 \%$ uncertainty on the average wind speed, which is a common accuracy requirement at these wind speeds (Wentz et al. 2017).

\section{b. Sensitivity to vertical wind profile}

Figure 7 displays the sensitivity of the WindSatplatform anemometer biases to the choice of vertical profile used to convert platform winds to a 10-m height. The black curve and associated error bars in Fig. 7 refer to the power law with $\alpha=0.06$ and are the same as the ones shown in Fig. 6, while the remaining curves show WindSat-anemometer $10-\mathrm{m}$ wind biases calculated using the power law with $\alpha=0.04$ and $\alpha=0.08$ as well as the logarithmic wind profile. This figure shows that the differences between these four various vertical profiles 


\section{gullfaksc, WIB, Windsat-Platform Bias 2006-2016}
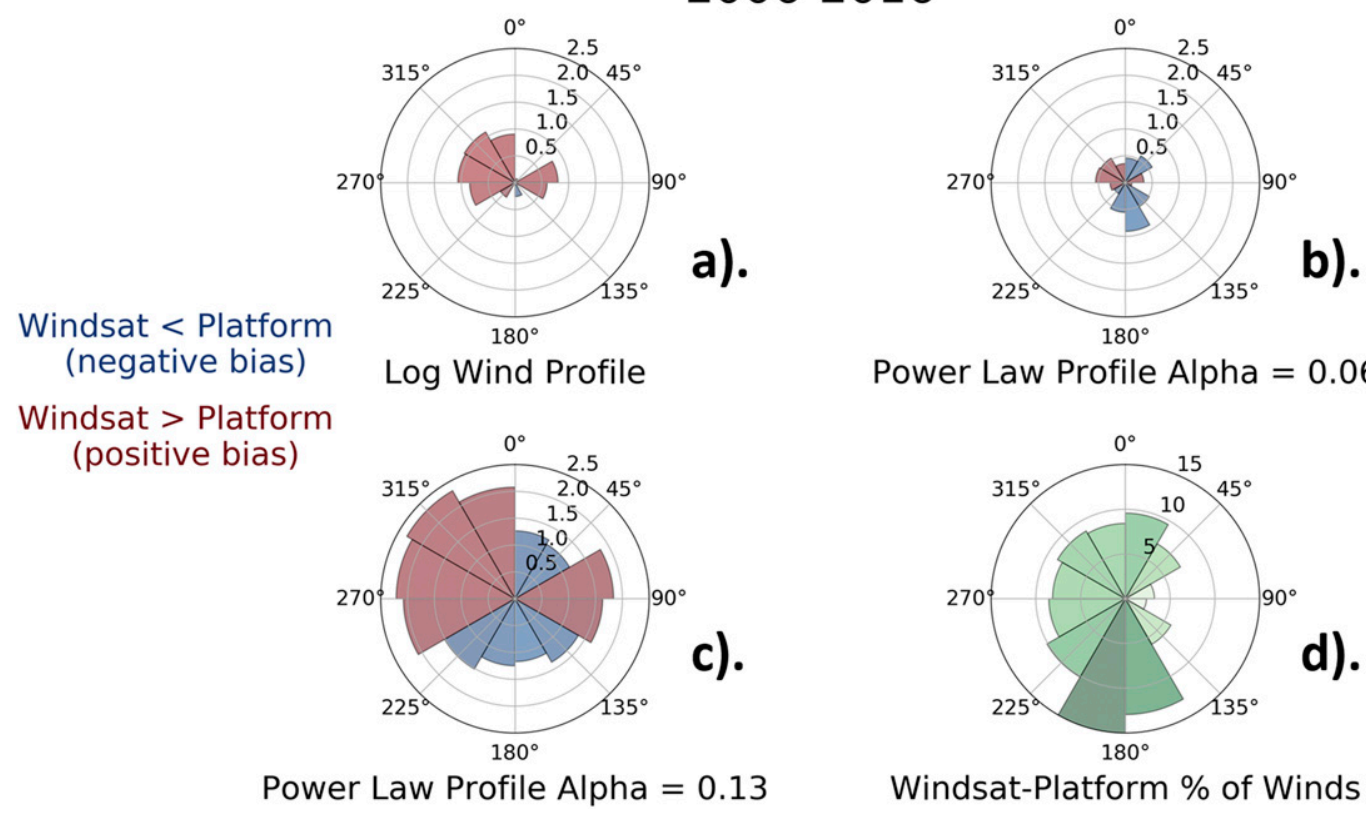

Power Law Profile Alpha $=0.06$

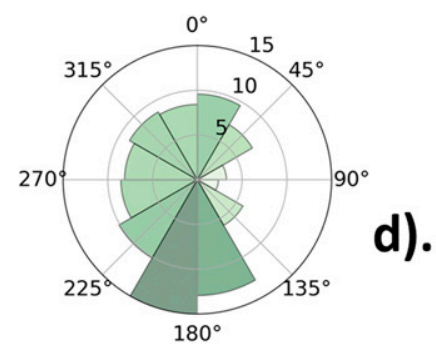

Windsat-Platform \% of Winds

FIG. 5. (a)-(c) The WindSat-anemometer wind directional biases in $30^{\circ}$ bins for the 3 different anemometer $10-\mathrm{m}$ winds at platform Gullfaks-C, anemometer WIB 2006-16. (d) The percentage of measurements that fall in each wind direction bin. In (a)-(c), red shading indicates bins where the average WindSat-anemometer bias is positive, while blue shading indicates bins where the average WindSat-anemometer bias is negative.

lie within the uncertainty range that is indicated by the error bars.

Figure 7 illustrates that the $10-\mathrm{m}$ winds computed from the $\alpha=0.06$ power-law vertical wind profile are in best agreement with WindSat observations in the wind speed range between 5 and $15 \mathrm{~m} \mathrm{~s}^{-1}$, for which the high accuracy of the WindSat winds has been validated with moored buoy measurements and is therefore undisputed. This agrees with the results of the radiosondeanemometer comparison by Furevik and Haakenstad (2012), as discussed in section 3b. Based on this result, we have chosen the $\alpha=0.06$ power law to calculate the 10 -m platform wind speeds $W_{10 \mathrm{~m}}$ for our validation study at all wind speeds.

\section{c. Results for other satellites}

The good agreement between these platform anemometer and satellite winds is not limited to comparisons with WindSat during the 2003-16 time period, but extends to other satellite sensors across varying time periods as well. This is illustrated in Fig. 8, which shows satellite-anemometer bias as a function of the average satellite/anemometer wind speed for the following satellite sensors in addition to WindSat: (i) AMSR2 from 2012 to 2016, (ii) AMSR-E from 2003 to 2011, (iii) ASCAT from 2007 to 2016, and (iv) QuikSCAT from 2003 to 2009.
The time periods were chosen to allow the best overlap and thus the best comparison with the WindSat time series. All available collocations of all satellite sensors and anemometers from those respective time periods were

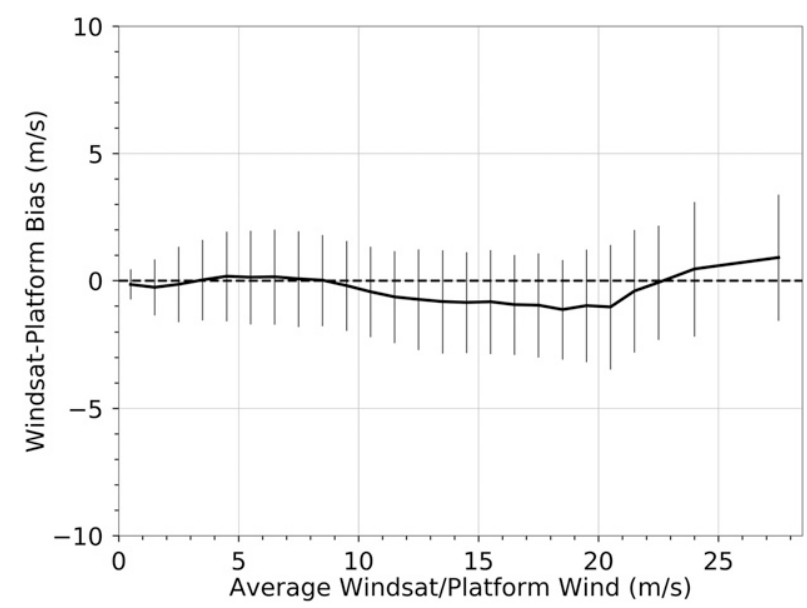

FIG. 6. WindSat-anemometer bias vs binned WindSat/anemometer average wind speed. Vertical bars represent \pm one standard deviation. Average wind speeds are separated into $1 \mathrm{~m} \mathrm{~s}^{-1}$ bins between 0 and $23 \mathrm{~m} \mathrm{~s}^{-1}$. Above $23 \mathrm{~m} \mathrm{~s}^{-1}$, the average wind speeds are concatenated into two larger bins (23-25 and $25-30 \mathrm{~m} \mathrm{~s}^{-1}$ ) in order to ensure sufficient population. The black dashed line represents the ideal case (no bias). 


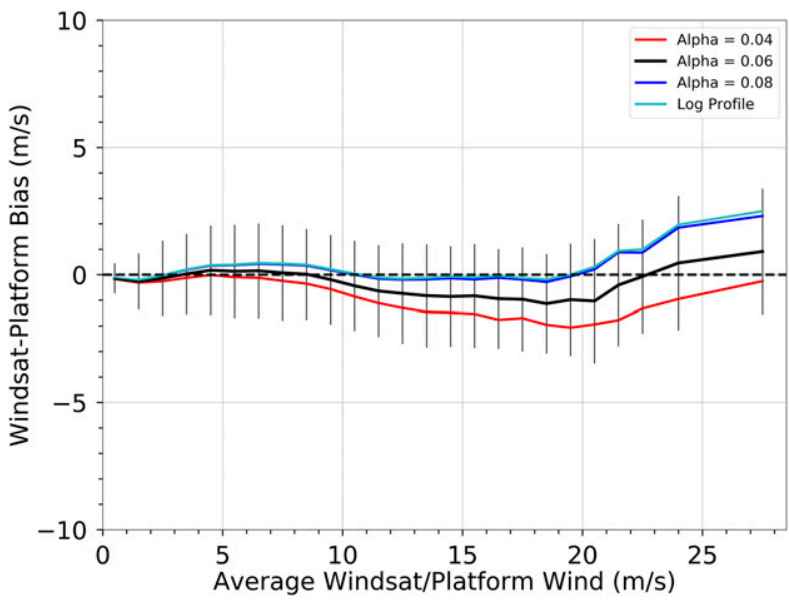

FIG. 7. As in Fig. 6, but with additional curves showing WindSatanemometer bias vs binned WindSat/anemometer average wind speed for $10-\mathrm{m}$ anemometer wind speeds calculated using the power law (1) with $\alpha=0.04$ (red) and 0.08 (dark blue) as well as the logarithmic profile (2) (light blue).

used in creating these curves. There are two things worth noting in this figure: 1 ) WindSat agrees very well with $10-\mathrm{m}$ anemometer wind speeds for different time periods, not just from 2003 to 2016. 2) The other sensors agree very well with the 10-m anemometer wind speeds and with WindSat. This agreement adds confidence to the validity of satellite wind measurements at wind speeds above $15 \mathrm{~m} \mathrm{~s}^{-1}$.

While Fig. 8 shows good agreement between satellites and the platform anemometers for overlapping satellite time periods, Fig. 9 takes this a step further by showing all satellite collocations with all QC selected anemometers for the entire time period between 1999 and 2016 for the six satellite sensors outlined in section 2b. Despite the fact that different satellite sensors were active during varying time periods, they all show good agreement with one another even at the highest wind speeds. In fact, in the highest wind speed bin $\left(25-30 \mathrm{~m} \mathrm{~s}^{-1}\right)$, the satellite-anemometer biases are all within approximately $2 \mathrm{~m} \mathrm{~s}^{-1}(\sim 7 \%-10 \%)$ of the average wind speed for all satellite sensors.

\section{d. Results for analysis wind speeds}

Figure 10 shows a comparison of all selected anemometers for the time period between 1999 and 2016 with wind speeds from the assimilation analyses described in section 2c. In contrast to the satellite-anemometer collocations shown in Fig. 9, the analyses in Fig. 10 generally

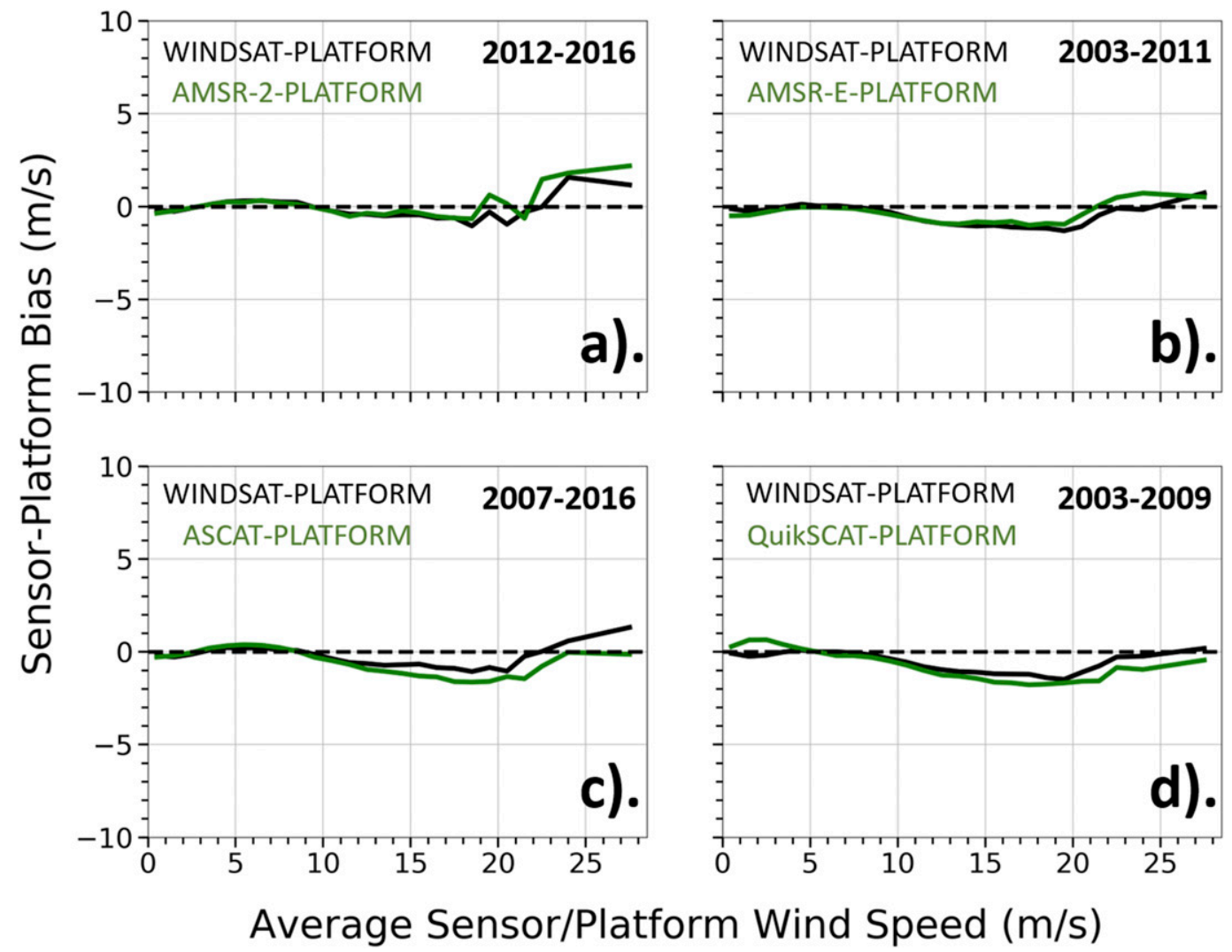

FIG. 8. Satellite-anemometer bias vs binned satellite/anemometer average wind speed for WindSat and (a) AMSR2 from 2012 to 2016, (b) AMSR-E from 2003 to 2011, (c) ASCAT from 2007 to 2016, and (d) QuikSCAT from 2003 to 2009. The black dashed lines represent the ideal cases (no bias). 


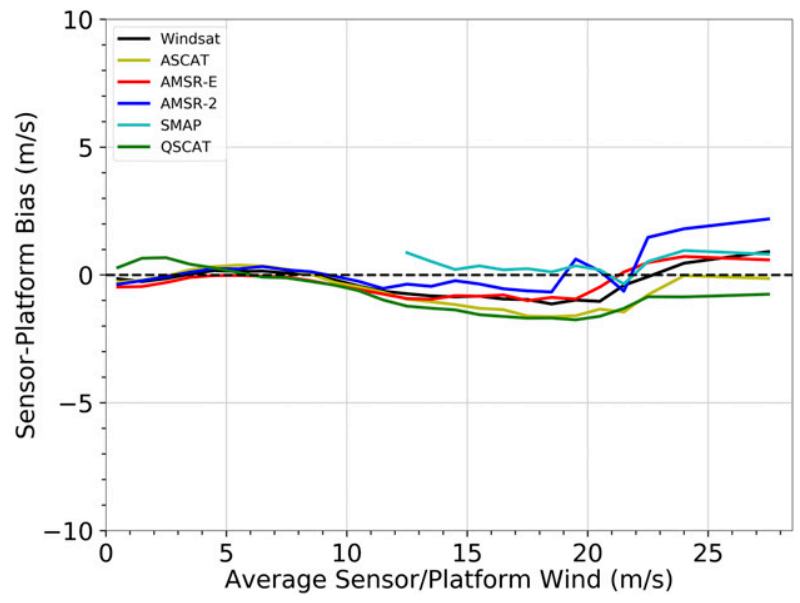

FIG. 9. Satellite-anemometer bias vs binned satellite/anemometer average wind speed for the 6 satellites mentioned in section $2 \mathrm{~b}$. Each curve was created using all available collocations between the sensor and the anemometers for the entire anemometer time period. Black line: WindSat. Green line: QuikSCAT. Yellow line: ASCAT. Red line: AMSR-E. Dark blue line: AMSR2. Light blue line: SMAP. The black dashed line represents the ideal case (no bias).

show poor agreement with anemometers at almost all wind speeds with the difference increasing as wind speed increases. In fact, the wind speed biases get as large as $25 \%$ at the highest wind speeds for certain models (green ECMWF curve in Fig. 10). This exceeds 2 times the standard deviation (error bars in Fig. 6). We explored whether this was due to the rather loose temporal collocation used when 6-hourly ECMWF wind fields were interpolated in space and time to the platform observations (green curve). To do this, we repeated the analysis used to create the green curve in Fig. 10 but only averaged platform winds that were observed within $2 \mathrm{~h}$ of the ECMWF analysis time [yellow curve in Fig. 10; following Bidlot et al. (2002), Saetra and Bidlot (2004), and https://confluence.ecmwf.int/display/WLW/ Verification + results]. It can be seen in Fig. 10 that this did not significantly alter the result, and both curves are very close to one another. Additionally, the black curve in Fig. 10 shows the difference between ECMWF and WindSat wind speeds for a triple matchup of ECMWF, WindSat, and platform observations. For the triple matchup, we have only included WindSat values that fall within $1 \mathrm{~h}$ of a quality-checked platform anemometer measurement in the same $0.25^{\circ} \times 0.25^{\circ}$ grid box as the platform. This curve illustrates that the biases between model wind speeds and platform wind speeds are of similar magnitude to the biases between model wind speeds and satellite wind speeds. The limited spatial resolution of the model wind speeds and possibly the proximity of these wind measurements to land are likely contributing factors to these biases.

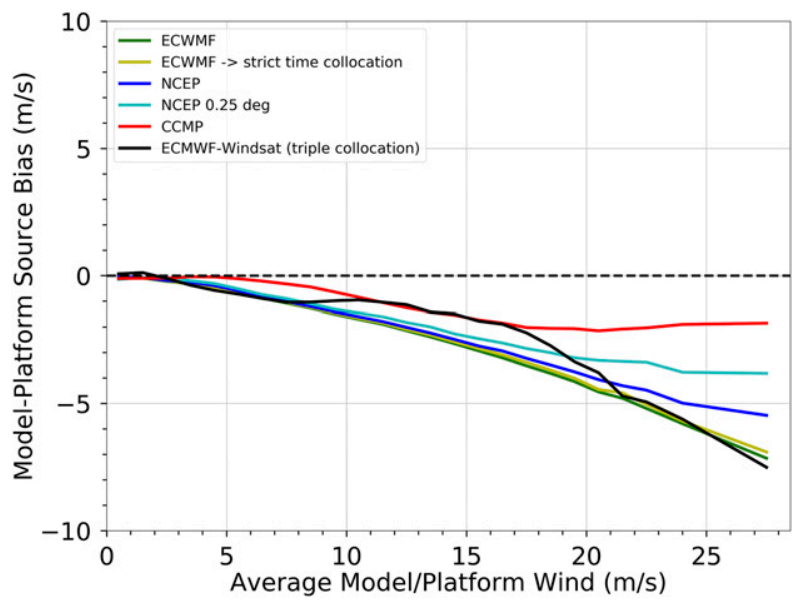

FIG. 10. Model-anemometer bias vs binned model/anemometer average wind speed for the 4 models described in section 2c. Dark blue line: $1^{\circ}$ NCEP. Light blue line: $0.25^{\circ}$ NCEP. Green line: ECMWF. Yellow line: ECMWF with a stricter time collocation $( \pm 2 \mathrm{~h})$. Red line: CCMP. Each of these curves was created using all available collocations between the model and the anemometers for the entire anemometer time period. The solid black line shows the difference between ECMWF and WindSat at the time and location of the platform anemometers using triple matchups between ECMWF, WindSat, and the platforms. The black dashed line represents the ideal case (no bias).

Our results for the ECMWF-anemometer and the satellite-anemometer comparisons are very similar to the ones presented in Pineau-Guillou et al. (2018). In their study, Pineau-Guillou et al. compare ECMWF and several satellites to $10-\mathrm{m}$ platform anemometer winds using much shorter time periods than the one used in our study. They considered several different winter storms in the northeast Atlantic from 2005 to 2015, each spanning several days. Despite the different matchups and quality control, the agreement with Pineau-Guillou et al. (2018) adds to the confidence in the results of both investigations.

The curve for NCEP $0.25^{\circ}$ analysis agrees slightly better with the platform anemometers than the ones for NCEP GDAS $1^{\circ}$ and ECMWF. This is likely due to the higher resolution of the NCEP GDAS $0.25^{\circ}$ model. A finer resolution leads to more accurate wind speeds when getting close to the coast.

Of all analyses winds in Fig. 10, CCMP compares best to the platform anemometers. CCMP ingests winds from most of the satellite sensors used in our study. If there are gaps in the satellite coverage due to the sampling pattern or presence of rain, then CCMP reverts to a background field from the ERA-Interim reanalysis, which is created by ECMWF. Because of this, it is not surprising that the result for CCMP lies between the result for ECMWF shown in Fig. 10 and the results for the satellite sensors shown in Fig. 9. 
TABLE 2. RMS error budget (in $\mathrm{m} \mathrm{s}^{-1}$ ) for the satellite-platform matchups at 2 different wind speeds $\left(W=10 \mathrm{~m} \mathrm{~s}^{-1}\right.$ and $W=$ $20 \mathrm{~m} \mathrm{~s}^{-1}$ ).

\begin{tabular}{llcc}
\hline & Error source & $W=10 \mathrm{~m} \mathrm{~s}^{-1}$ & $W=22 \mathrm{~m} \mathrm{~s}^{-1}$ \\
\hline 1 & Platform anemometer & 1.25 & $>1.25$ \\
2 & Noise (radiometer/ & 0.5 & 0.5 \\
& scatterometer) & & \\
3 & RTM/calibration & 0.5 & 0.5 \\
4 & Sampling mismatch & 0.9 & $>1.3$ \\
5 & Atmospheric stability & 0.4 & 0.8 \\
6 & Ocean currents & 0.5 & 0.5 \\
7 & Flow distortion & $<0.6$ & $<1.2$ \\
& $\quad$ Total observed & 1.9 & 2.5 \\
\hline
\end{tabular}

\section{Uncertainties and error budget}

We now discuss the various sources of uncertainties related to our satellite-anemometer wind speed comparison and estimate their magnitudes. Table 2 lists the root-mean-square (RMS) error allocations for the case of WindSat for the anemometer observations that have passed the QC (section 3e).

We provide error allocations for a moderate wind speed $W=10 \mathrm{~m} \mathrm{~s}^{-1}$, which is close to the observed average, and for a high wind speed $W=22 \mathrm{~m} \mathrm{~s}^{-1}$. The observed standard deviations between platform anemometer and WindSat winds are $1.9 \mathrm{~m} \mathrm{~s}^{-1}$ at $W=10 \mathrm{~m} \mathrm{~s}^{-1}$ and $2.5 \mathrm{~m} \mathrm{~s}^{-1}$ at $W=22 \mathrm{~m} \mathrm{~s}^{-1}$. The biases are close to zero in both cases. We identify the following uncertainty contributions:

1) Errors in the anemometer measurement itself: $\mathrm{We}$ can estimate their size from the analysis of Furevik and Haakenstad (2012), who compared different platform anemometer winds that were measured at the same site and with winds from radiosondes at the platform sites (Table 3 in their paper). This leads to an allocation for the platform anemometer uncertainty estimate of about $1.25 \mathrm{~m} \mathrm{~s}^{-1}$. We use this value for both $W=10 \mathrm{~m} \mathrm{~s}^{-1}$ and $W=22 \mathrm{~m} \mathrm{~s}^{-1}$, though it is possible that this error increases with increasing wind speed.

2) Random noise in the satellite sensor: We estimate this contribution to be $0.5 \mathrm{~m} \mathrm{~s}^{-1}$ (Wentz 1997), independent of wind speed.

3) Other errors in the satellite wind retrieval: These include the radiative transfer model (RTM) used in the retrievals and errors in the sensor calibration. Both causes are not easy to disentangle. We estimate an error of $0.5 \mathrm{~m} \mathrm{~s}^{-1}$ based on Wentz (1997). This is independent of wind speed.

4) Residual spatial-temporal sampling mismatch error between the satellite and the anemometer measurement: This arises due to the spatial gradients and temporal advection of the wind field within the satellite footprint. Wentz (1997) estimated the size of this effect to be about $0.9 \mathrm{~m} \mathrm{~s}^{-1}$ at average wind speeds for satellite-buoy comparisons. It is appropriate to assume a similar magnitude for our satellite-platform anemometer comparison at $W=10 \mathrm{~m} \mathrm{~s}^{-1}$. It can be expected that the size of the mismatch error increases with increasing wind speed, but at this point it is difficult to estimate how much.

5) Uncertainty in the vertical wind profile due to lack of knowledge in the atmospheric stability at the observation time: We have used a power law profile with $\alpha=0.06$ in order to reference the platform winds to $10 \mathrm{~m}$. This is based on assuming neutral stability conditions (Furevik and Haakenstad 2012). The majority of matchups fall into this category (section $3 b)$. The range of atmospheric stability conditions and the resulting variation in the $10-\mathrm{m}$ platform wind speed can be assessed from Fig. 7. The corresponding error is proportional to wind speed. We estimate these to be $0.4 \mathrm{~m} \mathrm{~s}^{-1}$ at $W=10 \mathrm{~m} \mathrm{~s}^{-1}$ and $0.8 \mathrm{~m} \mathrm{~s}^{-1}$ at $W=22 \mathrm{~m} \mathrm{~s}^{-1}$. The study by Kettle (2015) indicates that the majority of cases at high wind speeds measured by the platforms occur during strong extratropical cyclones in the winter months where the atmosphere is unstable. This indicates that in those instances it might be more appropriate to use a power law with $\alpha=0.04$ rather than $\alpha=0.06$ when calculating the $10-\mathrm{m}$-converted anemometer winds. As a result, our analysis would systematically underestimate the platform winds by about $0.8 \mathrm{~m} \mathrm{~s}^{-1}$ at high wind speeds and thus the curves in Figs. 6, 8, 9, and 10 would need to be shifted down by that amount in the very high wind speed range.

6) Neglecting ocean surface currents: Satellite data measure wind speeds relative to the moving ocean surface, while the platform anemometers measure the wind speed relative to Earth. The typical surface currents in the regions of the North and Norwegian Seas where the platforms are located are mostly below $0.5 \mathrm{~m} \mathrm{~s}^{-1}$ and seldom get higher than $1.0 \mathrm{~m} \mathrm{~s}^{-1}$ (oceancurrents.rsmas.miami.edu/atlantic/ norwegian_2.html). The ocean current vector needs to be added to or subtracted from the wind speed vector. Because the wind direction itself varies over the whole range between $0^{\circ}$ and $360^{\circ}$, we treat the ocean currents as random error source and estimate a value of about $0.5 \mathrm{~m} \mathrm{~s}^{-1}$ at $W=10 \mathrm{~m} \mathrm{~s}^{-1}$ and at $W=22 \mathrm{~m} \mathrm{~s}^{-1}$.

7) Possible distortion of the wind field around the oil platform: This can depend on height and position of the anemometer mounting on the platform, and it could result in both high or low biases in the platform anemometer winds. Because of that we treat it as 
random error source. Our analysis (section 3f) did not reveal any significant bias of the platform anemometer wind speed with respect to wind direction for the observations that passed the QC. Thus, we can conclude that the position of the anemometer mounting with respect to wind direction is not a major source of flow distortion. We can estimate the size of the possible flow distortion from the RMS error budget in Table 2. As the uncertainties 1-7 are independent, their mean squares add up to the observed value. Using the numbers for 1-6 in the case of $W=10 \mathrm{~m} \mathrm{~s}^{-1}$, we obtain a value of $0.6 \mathrm{~m} \mathrm{~s}^{-1}$ for the remaining contribution 7 . This value is an upper limit for possible flow distortion at this wind speed. It is reasonable to assume that flow distortion increases roughly proportionally with wind speed, which results in an allocation of $1.2 \mathrm{~m} \mathrm{~s}^{-1}$ or less at $W=22 \mathrm{~m} \mathrm{~s}^{-1}$. Employing the mean square addition of the uncertainties, we obtain an estimate of $1.3 \mathrm{~m} \mathrm{~s}^{-1}$ for the sampling mismatch error in the budget at $W=22 \mathrm{~m} \mathrm{~s}^{-1}$, which was still missing in the error budget.

We note that neither the neglecting of ocean surface currents nor possible flow distortion appear to be major drivers in the error budgets.

\section{Summary and conclusions}

The objective of this study was to validate satellite measurements of the ocean surface winds for high wind speeds, above $15 \mathrm{~m} \mathrm{~s}^{-1}$, versus in situ observations. The validation source considered here was provided by anemometers mounted on oil platforms in the North and Norwegian Seas off the coast of Norway.

We have compared 10-m ocean wind speeds from six different satellite microwave sensors (WindSat, QuikSCAT, ASCAT, AMSR-E, AMSR2, and SMAP) and four different analyses/models (NCEP GDAS $1^{\circ}$, NCEP GDAS $0.25^{\circ}$, ECMWF, CCMP) to wind measurements from anemometers on 10 different oil platforms. The time frame of the satellite-platform anemometer matchups spans from 1999 to 2016. The oil platform anemometers are mounted at different heights between 40 and $140 \mathrm{~m}$, and we have converted the anemometer winds to a height of $10 \mathrm{~m}$ in order to make meaningful comparisons with the satellite winds. We have performed a series of rigorous quality checks to reject some anemometer time series with poor correlation to satellite/model observations in the wind speed range $0-15 \mathrm{~m} \mathrm{~s}^{-1}$, where the validity of the satellite winds is well established. We have also rejected anemometer time series if they exhibit discontinuities or anomalies.

Additionally, we have explored the sensitivity of the 10-m-converted wind speed to the choice of the vertical wind profile. The 10-m-converted anemometer wind speeds were calculated with different vertical wind profiles. It was found that the power-law profile with $\alpha=0.06$ showed the best agreement with the satellite winds. This is consistent with the findings by Furevik and Haakenstad (2012), who have compared platform anemometer winds and radiosonde measurements of vertical wind profiles in the North and Norwegian Seas.

The longest overlap between platform anemometer and satellite winds was provided by WindSat (2003-16). A comparison of the collective anemometer 10-m wind time series determined using the power-law profile with $\alpha=0.06$ versus collocated WindSat winds showed that the two wind datasets are very consistent with each other. The agreement is excellent in the well-established wind speed range $0-15 \mathrm{~m} \mathrm{~s}^{-1}$ and very good at all wind speeds between 15 and $30 \mathrm{~m} \mathrm{~s}^{-1}$. The agreement between WindSat and platform winds is $10 \%$ or better and lies well within the margins of error. Similar good agreement was found for the matchups between the platform winds and the other satellites (QuikSCAT, ASCAT, AMSRE, AMSR2, and SMAP) for the respective overlapping time periods.

Conversely, the NCEP GDAS and ECMWF model winds at these particular locations in the North Sea showed poor agreement with the quality-controlled platform anemometers. The model wind speeds are biased low at high winds when compared to both platform satellite winds. The size of the bias grows with increasing wind speeds, becoming as large as $25 \%$ at the highest wind speeds.

Our results are consistent with the previous study by Pineau-Guillou et al. (2018), in which platform winds in the northeast Atlantic were compared to satellite and model-simulated surface winds and wind measurements from moored buoys for several sample storms between 2005 and 2015. Pineau-Guillou et al. (2018) found that, above $20 \mathrm{~m} \mathrm{~s}^{-1}$, satellite-based observations generally agreed well with platform winds, while buoy and model winds were up to $20 \%$ lower.

Our study builds on those early results and extends the comparison of platform versus satellite winds for the whole period of availability (1999 to 2016). Robust results are needed in order to resolve the debate about the validation of satellite winds in the range $20-30 \mathrm{~m} \mathrm{~s}^{-1}$. For this reason, the quality control (section 3 ) and uncertainty analysis (section 5) were essential components of our investigation.

In conclusion, we have demonstrated that, within a reasonable margin of uncertainty, the anemometer winds from oil platforms in the Norwegian and North Seas provide a reliable source of in situ wind measurements for matchup with satellite winds. We have found 
agreement between the satellite and anemometers winds within the margins of error for the wind speeds up to $30 \mathrm{~m} \mathrm{~s}^{-1}$. This provides a valuable validation of satellite winds in a wind speed range where other reliable validation sources are scarce.

Acknowledgments. This research was supported by the NASA SMAP Science Utilization Program SUSMAP (Contract NNH17CA04C) and the NASA Ocean Vector Winds Science Team OVWST (Contract NNH14CM09C). We thank Øyvind Breivik from the Norwegian Meteorological Institute for providing us with the platform anemometer measurements and Mark Bourassa from COAPS at FSU for his help acquiring these data. We are also grateful to Lucia Pineau-Guillou (IFREMER, France) and Brigitte Furevik (Norwegian Meteorological Institute) for useful discussions on this subject.

\section{REFERENCES}

Atlas, R., R. N. Hoffman, J. Ardizzone, S. M. Leidner, J. C. Jusem, D. K. Smith, and D. Gombos, 2011: A cross-calibrated, multiplatform ocean surface wind velocity product for meteorological and oceanographic applications. Bull. Amer. Meteor. Soc., 92, 157-174, https://doi.org/10.1175/2010BAMS2946.1.

Bidlot, J. R., D. J. Holmes, P. A. Wittmann, R. Lalbeharry, and H. S. Chen, 2002: Intercomparison of the performance of operational ocean wave forecasting systems with buoy data. Wea. Forecasting, 17, 287-310, https://doi.org/10.1175/1520-0434(2002) 017<0287:IOTPOO > 2.0.CO;2.

Bourassa, M. A., S. T. Gille, D. L. Jackson, J. B. Roberts, and G. A. Wick, 2010: Ocean winds and turbulent air-sea fluxes inferred from remote sensing. Oceanography, 23 (4), 36-51, https://doi.org/ 10.5670/oceanog.2010.04.

Draper, D. W., and D. G. Long, 2004: Evaluating the effect of rain on SeaWinds scatterometer measurements. J. Geophys. Res., 109, C02005, https://doi.org/10.1029/2002JC001741.

Ebuchi, N., H. C. Graber, and M. J. Caruso, 2002: Evaluation of wind vectors observed by QuikSCAT/SeaWinds using ocean buoy data. J. Atmos. Oceanic Technol., 19, 2049-2062, https:// doi.org/10.1175/1520-0426(2002)019<2049:EOWVOB > 2.0.CO;2.

Fore, A. G., S. H. Yueh, W. Tang, B. W. Stiles, and A. K. Hayashi, 2016: Combined active/passive retrievals of ocean vector wind and sea surface salinity with SMAP. IEEE Trans. Geosci. Remote Sens., 54, 7396-7404, https://doi.org/10.1109/ TGRS.2016.2601486.

Furevik, B. R., and H. Haakenstad, 2012: Near-surface marine wind profiles from rawinsonde and NORA10 hindcast. J. Geophys. Res., 117, D23106, https://doi.org/10.1029/ 2012JD018523.

Hersbach, H., 2008: CMOD5.n: A C-band geophysical model function for equivalent neutral wind. ECMWF Tech. Memo. $554,20 \mathrm{pp}$.

— 2010: Comparison of C-band scatterometer CMOD5.n equivalent neutral winds with ECMWF. J. Atmos. Oceanic Technol., 27, 721-736, https://doi.org/10.1175/2009JTECHO698.1.

Hilburn, K. A., and F. J. Wentz, 2008: Intercalibrated passive microwave rain products from the Unified Microwave Ocean
Retrieval Algorithm (UMORA). J. Appl. Meteor. Climatol., 47, 778-794, https://doi.org/10.1175/2007JAMC1635.1.

, $—$, D. K. Smith, and P. D. Ashcroft, 2006: Correcting active scatterometer data for the effects of rain using passive radiometer data. J. Appl. Meteor. Climatol., 45, 382-398, https:// doi.org/10.1175/JAM2357.1.

Howden, S., D. Gilhousen, N. Guinasso, J. Walpert, M. Sturgeon, and L. Bender, 2008: Hurricane Katrina winds measured by a buoy-mounted sonic anemometer. J. Atmos. Oceanic Technol., 25, 607-616, https://doi.org/10.1175/2007JTECHO518.1.

Kettle, A. J., 2015: A diagram of wind speed versus air-sea temperature difference to understand the marine atmospheric boundary layer. Energy Procedia, 76, 138-147, https://doi.org/ 10.1016/j.egypro.2015.07.879.

Klotz, B. W., and E. W. Uhlhorn, 2014: Improved Stepped Frequency Microwave Radiometer tropical cyclone surface winds in heavy precipitation. J. Atmos. Oceanic Technol., 31, 2392-2408, https://doi.org/10.1175/JTECH-D-14-00028.1.

Large, W. G., J. Morzel, and G. B. Crawford, 1995: Accounting for surface wave distortion of the marine wind profile in low-level ocean storms wind measurements. J. Phys. Oceanogr., 25, 2959-2971, https://doi.org/10.1175/1520-0485(1995)025<2959: AFSWDO $>2.0 . \mathrm{CO} ; 2$.

Liu, W. T., and W. Tang, 1996: Equivalent neutral wind. JPL Publ. 96-17, 22 pp., https://ntrs.nasa.gov/search.jsp?R=19970010322.

Mears, C. A., D. K. Smith, and F. J. Wentz, 2001: Comparison of special sensor microwave imager and buoy-measured wind speeds from 1987 to 1997. J. Geophys. Res., 106,11 719-11 729, https://doi.org/10.1029/1999JC000097.

Meissner, T., and F. J. Wentz, 2009: Wind-vector retrievals under rain with passive satellite microwave radiometers. IEEE Trans. Geosci. Remote Sens., 47, 3065-3083, https://doi.org/ 10.1109/TGRS.2009.2027012.

- and - 2012: The emissivity of the ocean surface between 6 and $90 \mathrm{GHz}$ over a large range of wind speeds and Earth incidence angles. IEEE Trans. Geosci. Remote Sens., 50, 3004-3026, https://doi.org/10.1109/TGRS.2011.2179662.

_ L. Ricciardulli, and F. J. Wentz, 2017: Capability of the SMAP mission to measure ocean surface winds in storms. Bull. Amer. Meteor. Soc., 98, 1660-1677, https://doi.org/ 10.1175/BAMS-D-16-0052.1.

一,- , and — 2018: Remote Sensing Systems SMAP daily sea surface winds speeds on $0.25 \mathrm{deg}$ grid, FINAL, version 01.0. Remote Sensing Systems, accessed 15 November 2017, www.remss.com/missions/smap/.

Peixoto, J., and A. Oort, 1991: Physics of Climate. American Institute of Physics, $520 \mathrm{pp}$.

Pineau-Guillou, L., F. Ardhuin, M. N. Bouin, J. L. Redelsperger, B. Chapron, J. R. Bidlot, and Y. Quilfen, 2018: Strong winds in a coupled wave-atmosphere model during a North Atlantic storm event: Evaluation against observations. Quart. J. Roy. Meteor. Soc., 144, 317-332, https://doi.org/10.1002/qj.3205.

Poe, G. A., 1990: Optimum interpolation of imaging microwave radiometer data. IEEE Trans. Geosci. Remote Sens., 28, 800-810, https://doi.org/10.1109/36.58966.

Portabella, M., A. Stoffelen, W. Lin, A. Turiel, A. Verhoef, J. Verspeek, and J. Ballabrera-Poy, 2012: Rain effects on ASCAT-retrieved winds: Toward an improved quality control. IEEE Trans. Geosci. Remote Sens., 50, 2495-2506, https:// doi.org/10.1109/TGRS.2012.2185933.

Renfrew, I. A., G. N. Petersen, D. A. J. Sproson, G. W. K. Moore, H. Adiwidjaja, S. Zhang, and R. North, 2009: A comparison of aircraft-based surface-layer observations over Denmark Strait 
and the Irminger Sea with meteorological analyses and QuikSCAT winds. Quart. J. Roy. Meteor. Soc., 135, 2046-2066, https://doi.org/10.1002/qj.444.

Reul, N., B. Chapron, E. Zabolotskikh, C. Donlon, Y. Quilfen, S. Guimbard, and J. F. Piolle, 2016: A revised L-band radiobrightness sensitivity to extreme winds under tropical cyclones: The five year SMOS-storm database. Remote Sens. Environ., 180, 274-291, https://doi.org/10.1016/j.rse.2016.03.011.

— size measurements from space. Bull. Amer. Meteor. Soc., 98 , 2367-2385, https://doi.org/10.1175/BAMS-D-15-00291.1.

Ricciardulli, L., 2016: ASCAT on MetOp-A data product update notes. Remote Sensing Systems Tech. Rep. 40416, 5 pp.

, and F. J. Wentz, 2015: A scatterometer geophysical model function for climate-quality winds: QuikSCAT Ku-2011. J. Atmos. Oceanic Technol., 32, 1829-1846, https://doi.org/ 10.1175/JTECH-D-15-0008.1.

$\longrightarrow$, and —, 2016: Remote Sensing Systems ASCAT C-2015 daily ocean vector winds on $0.25 \mathrm{deg}$ grid, version 2.1 . Remote Sensing Systems, accessed 15 November 2017.

—_ _ a and D. K. Smith, 2011: Remote Sensing Systems QuikSCAT Ku-2011 daily orbital swath ocean vector winds L2B, version 4. Remote Sensing Systems, accessed 15 November 2017, www.remss.com/missions/qscat.

Saetra, Ø., and J. R. Bidlot, 2004: Potential benefits of using probabilistic forecasts for waves and marine winds based on the ECMWF Ensemble Prediction System. Wea. Forecasting, 19, 673-689, https://doi.org/10.1175/1520-0434(2004) 019<0673:PBOUPF $>2.0 . \mathrm{CO} ; 2$.

Sampson, C. R., and A. J. Schrader, 2000: The automated Tropical Cyclone Forecasting System (version 3.2). Bull. Amer. Meteor. Soc., 81, 1231-1240, https://doi.org/10.1175/1520-0477(2000) $081<1231$ :TATCFS $>2.3$.CO;2.

Skey, S. G. P., and M. D. Miles, 1999: Advances in buoy technology for wind/wave data collection and analysis. OCEANS'99, Seattle, WA, IEEE, 113-118, https://doi.org/10.1109/OCEANS.1999.799716.

Soisuvarn, S., Z. Jelenak, P. S. Chang, S. O. Alsweiss, and Q. Zhu, 2013: CMOD5.h-A high wind geophysical model function for C-band vertically polarized satellite scatterometer measurements. IEEE Trans. Geosci. Remote Sens., 51, 3744-3760, https://doi.org/10.1109/TGRS.2012.2219871.

Stiles, B. W., and S. H. Yueh, 2002: Impact of rain on spaceborne $\mathrm{Ku}$-band wind scatterometer data. IEEE Trans. Geosci. Remote Sens., 40, 1973-1983, https://doi.org/10.1109/TGRS.2002.803846.

Stoffelen, A., J. A. Verspeek, J. Vogelzang, and A. Verhoef, 2017: The CMOD7 geophysical model function for ASCAT and ERS wind retrievals. IEEE J. Sel. Top. Appl. Earth Obs. Remote Sens., 10, 2123-2134, https://doi.org/10.1109/JSTARS.2017.2681806.

Stogryn, A., 1978: Estimates of brightness temperatures from scanning radiometer data. IEEE Trans. Antennas Propag., 26, 720-726, https://doi.org/10.1109/TAP.1978.1141919.

Taylor, P. K., and M. J. Yelland, 2001: The dependence of sea surface roughness on the height and steepness of the waves. J. Phys. Oceanogr., 31, 572-590, https://doi.org/10.1175/ 1520-0485(2001)031<0572:TDOSSR >2.0.CO;2.

Tournadre, J., and Y. Quilfen, 2003: Impact of rain cell on scatterometer data: 1 . Theory and modeling. J. Geophys. Res., $\mathbf{1 0 8}$, 3225, https://doi.org/10.1029/2002JC001428.
Uhlhorn, E. W., and P. G. Black, 2003: Verification of remotely sensed sea surface winds in hurricanes. J. Atmos. Oceanic Technol., 20, 99-116, https://doi.org/10.1175/1520-0426(2003) $020<0099$ :VORSSS $>2.0$. CO 2 .

, — J. L. Franklin, M. Goodberlet, J. Carswell, and A. S. Goldstein, 2007: Hurricane surface wind measurements from an operational stepped frequency microwave radiometer. Mon. Wea. Rev., 135, 3070-3085, https://doi.org/10.1175/ MWR3454.1.

Verhoef, A., M. Portabella, A. Stoffelen, and H. Hersbach, 2008: CMOD5.n-The CMOD5 GMF for neutral winds. KNMI Tech. Note SAF/OSI/CDOP/KNMI/TEC/TN/3, $13 \mathrm{pp}$.

Verspeek, J., A. Stoffelen, M. Portabella, H. Bonekamp, C. Anderson, and J. F. Saldaña, 2010: Validation and calibration of ASCAT using CMOD5.n. IEEE Trans. Geosci. Remote Sens., 48, 386-395, https://doi.org/10.1109/TGRS.2009.2027896.

Weissman, D. E., and M. A. Bourassa, 2008: Measurements of the effect of rain-induced sea surface roughness on the QuikSCAT scatterometer radar cross section. IEEE Trans. Geosci. Remote Sens., 46, 2882-2894, https://doi.org/10.1109/ TGRS.2008.2001032.

Wentz, F. J., 1997: A well-calibrated ocean algorithm for special sensor microwave/imager. J. Geophys. Res., 102, 8703-8718, https://doi.org/10.1029/96JC01751.

—, and R. W. Spencer, 1998: SSM/I rain retrievals within a unified all-weather ocean algorithm. J. Atmos. Sci., 55, 16131627, https://doi.org/10.1175/1520-0469(1998)055<1613: SIRRWA $>2.0 . \mathrm{CO} ; 2$.

—_, L. Ricciardulli, C. Gentemann, T. Meissner, K. A. Hilburn, and J. Scott, 2013: Remote Sensing Systems Coriolis WindSat daily environmental suite on $0.25 \mathrm{deg}$ grid, version 7. Remote Sensing Systems, accessed 15 November 2017, www.remss.com/missions/windsat.

_, T. Meissner, C. Gentemann, K. A. Hilburn, and J. Scott, 2014a: Remote Sensing Systems GCOM-W1 AMSR2 daily environmental suite on $0.25 \mathrm{deg}$ grid, version 8 . Remote Sensing Systems, accessed 15 November 2017, www.remss.com/ missions/amsr.

,,--- , and M. Brewer, 2014b: Remote Sensing Systems AQUA AMSR-E daily environmental suite on 0.25 deg grid, version 7. Remote Sensing Systems, accessed 15 November 2017, www.remss.com/missions/amsr.

_ J. Scott, R. Hoffman, M. Leidner, R. Atlas, and J. Ardizzone, 2015: Remote Sensing Systems Cross-Calibrated MultiPlatform (CCMP) 6-hourly ocean vector wind analysis product on 0.25 deg grid, version 2.0. Remote Sensing Systems, accessed 15 November 2017, www.remss.com/measurements/ccmp.

_ - and Coauthors, 2017: Evaluating and extending the ocean wind climate data record. IEEE J. Sel. Top. Appl. Earth Obs. Remote Sens., 10, 2165-2185, https://doi.org/10.1109/ JSTARS.2016.2643641.

Zabolotskikh, E., L. Mitnik, and B. Chapron, 2014: GCOM-W1 AMSR2 and MetOp-A ASCAT wind speeds for the extratropical cyclones over the North Atlantic. Remote Sens. Environ., 147, 89-98, https://doi.org/10.1016/j.rse.2014.02.016.

Zeng, L., and R. A. Brown, 1998: Scatterometer observations at high wind speeds. J. Appl. Meteor., 37, 1412-1420, https://doi.org/ 10.1175/1520-0450(1998)037<1412:SOAHWS > 2.0.CO;2. 